\title{
Spatial Management of Invasive Species: Pathways and Policy Options
}

\author{
James N. Sanchirico • Heidi J. Albers • \\ Carolyn Fischer · Conrad Coleman
}

Accepted: 23 September 2009 / Published online: 1 November 2009

(C) The Author(s) 2009. This article is published with open access at Springerlink.com

\begin{abstract}
In addressing the problem of invasive species, decision makers have a variety of options, each targeting different aspects as it evolves over time and space. We develop a 2-region bioeconomic model that includes several transmission pathways that spread the invader. Within each region, inspections, removal efforts, and sustainable land management practices, including habitat restoration and less damaging production activities, are available to the regulator. We investigate the implications of different transmission pathways and second-best policies on the control patterns and invasive populations. Second-best settings where certain controls are not available to the regulator result in large distortions on the optimal use of the land. Overall, we find that non-linear interactions between regions, pathways, and controls are significant determinants of the optimal management of invasive species.
\end{abstract}

Keywords Metapopulation - Ecosystem services · Optimal control · Bioeconomic · Economic-ecological modeling

JEL Classification Q57 · Q27 · Q18

Electronic supplementary material The online version of this article (doi:10.1007/s10640-009-9326-0) contains supplementary material, which is available to authorized users.

J. N. Sanchirico $(\varangle)$

University of California at Davis, 1 Shields Ave, Davis, CA 95616, USA

e-mail: jsanchirico@ucdavis.edu

J. N. Sanchirico · C. Fischer · C. Coleman

Resources for the Future, Washington, DC 20036, USA

C. Fischer

e-mail: fischer@rff.org

H. J. Albers

Oregon State University, Corvallis, OR, USA

e-mail: HJ.Albers@oregonstate.edu 


\section{Introduction}

The ecological and economic damages of invasive species (denoted IAS) are gaining increasing attention in the scientific, conservation and policy arenas both domestically and internationally. The range of policy choices for addressing IAS includes reducing traderelated introductions through inspections and trade policy; curtailing establishment and spread through habitat management; controlling or eliminating existing infestations by removal efforts; mitigating damages by adapting management to levels of the IAS; and sacrificing native species and habitat to the IAS. To explore the complex interactions amongst IAS policies and amongst the numerous IAS transmission pathways, the paper develops and analyzes a two region bioeconomic model.

The economic literature on IAS has primarily focused on the temporal aspects of IAS control using only one or at most two of the potential policy options (Eiswerth and Kooten 2002; Horan et al. 2002; Leung et al. 2002; Olson and Roy 2005, 2008; Olson 2006; Mehta et al. 2007). Several papers focus on trade as a vector of introduction and invasion, including emphases on tariffs, inspections, and protectionism (McAusland and Costello 2004; Margolis et al. 2005; Costello et al. 2007). The ecological literature and some of the economics IAS literature examines ecological dispersal and invasion mechanisms (Finnoff et al. 2005; Davies and Sheley 2007).

Surprisingly, the impact of spatial aspects of IAS ecology and economics on optimal policies has not received as much attention in the economics literature. Indeed, several of the non-spatial papers on IAS and a literature review article discuss the need for examination of the effect of heterogeneity and spatial linkages on policy choice and effectiveness (Kaiser and Roumasset 2002; Leung et al. 2002; Olson 2006). Some noteworthy exceptions to the non-spatial approach include papers that emphasize agricultural pest damages over distance, barrier zones, species migration, spatial coordination, and wildlife disease (Hof 1998; Sharov and Liebhold 1998a,b; Sharov 2004; Horan et al. 2005; Skonhoft and Olaussen 2005; Carter et al. 2006; Wainger and King 2006).

Building off of the spatial literature, our 2-region model with IAS introductions and dispersal allows us to investigate the tradeoffs amongst a wide-range of controls. Because we explicitly incorporate two regions, several controls, and several transmission pathways, we are limited to focusing on the steady-state of the system. We use this framework to explore the interactions between multiple IAS transmission and dispersal pathways and to investigate the difference in policy recommendations from analysis that considers only a limited portfolio of control options (second-best scenario) to the case when all controls are available (first-best scenario).

Our comprehensive modeling framework includes the following components. First, there are three types of invasion and dispersal mechanisms: two related to economic activities that form transmission vectors and one ecological mechanism, where the species disperses from one region to the other. One type of "economic" transmission is represented by the flow of goods (e.g., imports) into the two regions (denoted foreign trade). This transmission pathway represents the IAS coming from outside the system and we account for the fact that greater levels of imports increases the extent of the invasion, and the other captures an interregional commerce or "domestic" trade pathway between the regions. ${ }^{1}$ In addition, once the

1 To be clear, the foreign and domestic trade labels are more of a mnemonic than they are meant to convey our modeling of the complex economic interactions within and between countries. That is, we do not develop a computable general equilibrium model to investigate invasive species control, which is an interesting area for future research. 
invasive species is established in one of the regions it can spread by an ecological dispersal processes.

Second, we link the transmission processes with the population biology of the species in each region where the dynamics depend on the quality of habitat in the region. Because the IAS engineers the stock of habitat (e.g., damages the habitat to make it more favorable for its survival), the greater the level of the infestation, the lower is the stock of habitat. The set of "ecosystem engineers"- species that modify, maintain, and create habitat often to their competitive advantage (Jones et al. 1994; Hastings et al. 2007)_includes beavers, Kudzu, zebra mussels, and cheatgrass. The damages from the IAS, therefore, are not only the lost grazing opportunities or clogged pipes but also the concomitant effects to the functioning of the ecosystem after their establishment. Because degraded habitats are more likely to be invaded (Huenneke et al. 1990; Cohen and Carlton 1998; Gordon 1998; Enserink 1999; Cumming 2002), the extent of transmission into a region from the trade or ecological dispersal vector is also a decreasing function of the quality of the habitat in the region. Both of these negative feedbacks result in faster growth rates of the invasive species.

Third, we model explicitly the ecological mechanisms that lead to economic damages, which in our stylized setting are the reduction in profits from commodity production (e.g., agriculture, grazing) less the costs of inspections, removal, and restoration efforts. In each region, commodity production is an increasing function of the quality of the habitat and we include the possibility of the use of a non-habitat input that can substitute for the habitat. By degrading the quality of the habitat, the invasive species reduces the value of the commodity production. We also account for the fact that excessive levels of the non-habitat input can also degrade the natural habitat that will in turn lead to greater infestation rates and further damages.

Overall, our framework permits us to highlight the trade-offs for a benevolent social planner that is considering simultaneously the prevention and treatment activities of IAS control across two regions. Prevention is accomplished through the use of inspections to reduce transmission both from outside and within the system and through more sustainable commodity production as a means to reduce the likelihood of the habitat being invaded. Treatment activities include direct removal efforts (e.g., weeding or pesticide application) that result in lower infestation levels and restoration activities that are investments in improving the quality of the habitat.

Our numerical analysis demonstrates that, when there are multiple pathways for IAS transmission, control strategies are not straightforward additive or average combinations of the results with a limited set of pathways because system-wide interactions are nonlinear. We develop the general 2-region model but then focus the analysis on the case of a port-inland regional structure both for ease of exposition and to represent spatial heterogeneity in our base case. Our results signal that policy recommendations from modeling efforts that only consider a subset of the dimensions and/or control strategies may be far from economically efficient and can lead to excessive ecological damages or abandonment of production activities. Similarly, we find that control strategies in the presence of spatially linked processes (IAS transmission) interact in a non-linear way with the degree of spatial heterogeneity. The implication is that conclusions from models that use proxies of spatial processes based on spatial heterogeneity (e.g., existence of a type of habitat) can make erroneous predictions for which even the direction of error is difficult to determine.

In the next section, we present the stylized bioeconomic metapopulation model and social planner's objective function. Subsequently, we investigate numerically the role of the dif- 
ferent transmission pathways relative to the base case of no pathways in a homogeneous economic and ecological system in order to isolate the effects of different spatial processes. We then introduce heterogeneity into the system to focus on the interaction of spatial linkages and heterogeneity. Finally, we conclude with an analysis of the implications of restricting the control set available to a planner in the presence of all pathways.

\section{Two-Region Bioeconomic Model}

Our bioeconomic model consists of two regions of heterogeneous habitat that are linked by trade and ecological transmission pathways. The social planner's (SP) problem is to maximize the return from commodity profits less the costs of treatment and prevention. Within each region, the production of the commodity can affect the rate at which invasions occur and the ecological growth rate of the IAS. The SP can undertake IAS removal efforts and/or can perform restoration activities that, by improving the quality of the habitat, slow the rate of IAS arrival and growth. Habitat quality is, however, assumed to be depleted based on the production of the commodity and damages due to the level of the IAS. In any period, the social planner makes the following policy choices: the level of inspections on domestic and foreign trade in each region, the amount of restoration to improve the habitat per region, the amount of IAS removal per region and the amount of the non-habitat input to apply in each region.

\subsection{Ecological Model}

The change over time in the amount of the IAS in each region relies on three components: invasion through trade and ecological dispersal, growth, and removal activities. Let the instantaneous rate of change of biomass $(x)$ of an IAS in region $i$ be equal to Eq. 1 where $f\left(x_{i}, x_{j}, H_{i}, V_{i}, I_{V_{i}}, I_{S_{i}}, S_{i}\right)$ is the biological production function in each period of the invasive species in region $i$, including ecological dispersal from the biomass in region $j$ and net additions from trade (these variables will be described in greater detail below); $R\left(x_{i}, E_{i}\right)$ is the removal production function in each period:

$$
d x_{i} / d t=f\left(x_{i}, x_{j}, H_{i}, V_{i}, I_{V_{i}}, I_{S_{i}}, S_{i}\right)-R\left(x_{i}, E_{i}\right)
$$

Before elaborating on the components in Eq. 1, we describe the equation of motion for $H_{i}$, a measure of ecosystem health of the habitat. Here, habitat health is a natural capital stock that can be depleted by production and invasion and replenished with restoration efforts. Equation 2 describes the instantaneous rate of change of the habitat, where $g\left(H_{i}, m_{i}\right)$ is the regenerative capacity function of the habitat, which can be supplemented by restoration/mitigation efforts $\left(m_{i}\right)$, and $D\left(A_{i}, x_{i}\right)$ is destruction or alteration of the habitat as a function of the level of the IAS $\left(x_{i}\right)$ and the use of inputs for commodity production in region $i\left(A_{i}\right)$. A simple formulation that captures the separate and increasing impact of commodity production and IAS levels is:

$$
d H_{i} / d t=g\left(H_{i}, m_{i}\right)-D\left(A_{i}, x_{i}\right)=(\underbrace{m_{i}}_{\text {Restoration }}+\underbrace{\left.\psi_{i}\right)\left(1-\frac{H_{i}}{H_{i}^{m}}\right) H_{i}}_{\begin{array}{c}
\text { Natural } \\
\text { regeneration }
\end{array}}-\underbrace{\left(\delta_{i, 1} A_{i}+\delta_{i, 2} x_{i}\right)}_{\text {Damages }}
$$

where $\psi_{i}$ is the intrinsic (natural) recovery rate of the habitat, $H_{i}^{m}$ is the natural (pristine) condition of the habitat, $A_{i}$ is the level of the non-habitat inputs in area $i, \delta_{i, 1}$ is the rate of 
damage to the habitat from the use of the non-natural input in the production of the commodity, $\delta_{i, 2}$ is the rate of habitat damage due to the invasive population within region $i$, and $m_{i}$ is the restoration rate. Both $m_{i}$ and $A_{i}$ are choice variables. Here, restoration augments the natural growth rate of the habitat, and the returns to investing in restoration decrease with the quality of the habitat stock.

\subsubsection{IAS Biological Production Function}

We modify the standard logistic population growth model to account for ecological dispersal, transmission through trade, and the potential role of habitat quality in reducing the growth of the invasive. Similar to the logistic model, the growth of the population is a function of the standing stock of the population. That is, the basis of our population model in each region is $a_{i} x_{i}\left(1-x_{i} / k_{i}\right)$, where $a_{i}$ is the growth rate and $k_{i}$ is the carrying capacity. To account for ecological dispersal, we expand the growth term $\left(a_{i} x_{i}\right)$ to include the possibility that individuals dispersing from the other region can contribute to growth in region $\mathrm{i}$ in any period. With this addition, we have $\left(a_{i} x_{i}+b_{i} x_{j}\right)\left(1-x_{i} / k_{i}\right)$ where $b_{j}$ is the ecological dispersal rate for species moving from region $\mathrm{j}$ to $\mathrm{i}$. This formulation was used to investigate the effects of marine reserve creation on economic efficiency (Sanchirico et al. 2006). Ecological dispersal between regions means that the IAS growth in one region is a function of the level of the IAS in the other region and ecological connectivity can allow invasion without a trade vector.

Two other sources of the IAS that can contribute to its population growth in any period are individuals piggybacking on either the movement of economic goods and services between the regions (denoted domestic trade) and the movement of goods and services from outside the two regions (denoted foreign trade). For example, many invasive grasses attach to cattle hides, cars, feedstocks (e.g., hay), and agricultural products, which are then moved between regions. Cocoons of the gypsy moth can attach to lawn equipment that is then moved between regions. The same type of process occurs with goods and services coming from outside the region. In both cases, inspections of these goods and services can control this movement. California, for example, inspects household goods for the cocoons of gypsy moths when individuals move into the state.

We model the effects of domestic and foreign trade transmission pathways on the growth of the invasive species by including two additional terms in the growth portion of the population dynamics. With these additions, we have $\left(a_{i} x_{i}+b_{i} x_{j}+\beta_{1, i} G\left(S_{i}, I_{s}, x_{j}\right)+\beta_{2, i} F\left(V_{i}, I_{v}\right)\right)$ $\left(1-x_{i} / k_{i}\right)$ where $\beta_{1, i}$ and $\beta_{2, i}$ are the rates of growth due to the introduction from domestic trade $G(\cdot)$, and foreign trade $F(\cdot)$, respectively. Specifically, these functions are

$$
F\left(V_{i}, I_{V_{i}}\right)=\left(\frac{V_{i}}{1+\varpi_{i} I_{V_{i}}}\right) \quad \text { and } \quad G\left(S_{i}, I_{S_{i}}, x_{j}\right)=\left(\frac{S_{i} x_{j}}{1+\omega_{i} I_{S_{i}}}\right)
$$

where $\left(\varpi_{i}, \omega_{i}\right)$ are scaling parameters.

Under these assumptions, transmission of the IAS through the trade vector increases with the volume of imports to region $i$ from foreign trade $\left(V_{i}\right)$ and from within the system or domestic trade $\left(S_{i}\right)$, and decreases with the level of inspections on foreign and domestic imports $\left(I_{V_{i}}, I_{S_{i}}\right.$ respectively). Population increases through domestic trade pathways also depend on the level of the invasive in the origin of the imports, where the spread term in region $i$ increases with the extent of invasion in region $j\left(x_{j}\right)$. Because IAS transmission through foreign goods is exogenous, eradication of the invasive population is only possible if inspections can drop the level of those incoming populations to zero. By assumption, $F(\cdot)$ can significantly reduce the level of incoming populations, but that level cannot be driven to zero unless the level of $V_{i}$ is zero. 
An additional component of the biological production function captures the role of habitat. Although eventually, without any removal efforts, the invasive species will reach its carrying capacity, the quality of the habitat can act to reduce the rate of growth of the invasive species. To account for the effects that habitats have on decisions regarding removal, we include the role of habitat in a multiplicatively separable fashion.

The final piece of Eq. 1 is the possible reduction of the IAS population through removal. We assume that the amount of infestation removed is likely to be an increasing function of effort, and it is likely to be an increasing function of the current state of invasion (making total eradication difficult). Therefore, removal activity is $R\left(x_{i}, E_{i}\right)=q_{i} E_{i} x_{i}$, where $q_{i}$ is the efficiency of a unit of control effort $\left(E_{i}\right)$ on reducing the population of the invasive species.

Putting all of the components together the IAS stock dynamics are

$$
\begin{aligned}
d x_{i} / d t= & \underbrace{\underbrace{a_{i} x_{i}}_{\begin{array}{c}
\text { Ecological } \\
\text { dispersal }
\end{array}}+\underbrace{b_{i} x_{j}}_{\begin{array}{c}
\text { Introductions from } \\
\text { other region }
\end{array}}+\beta_{2, i} \underbrace{F\left(V_{i}, I_{V_{i}}\right)}_{\begin{array}{c}
\text { Introductions } \\
\text { from outside } \\
\text { the region }
\end{array}}]}_{\begin{array}{c}
\text { Standing } \\
\text { stock }
\end{array}} \\
& \times \underbrace{\left(1-\frac{x_{i}}{k_{i}}\right)}_{\begin{array}{c}
\text { Drowth term } \\
\text { dependence }
\end{array}} \underbrace{\left(1-\frac{\left.\rho H_{i}, I_{S_{i}}, x_{j}\right)}{H_{i}^{m}}\right)}_{\begin{array}{c}
\text { Susceptibility } \\
\text { of the habitat }
\end{array}}-\underbrace{q_{i} E_{i} x_{i}}_{\begin{array}{c}
\text { Removal } \\
\text { activity }
\end{array}}
\end{aligned}
$$

where $\rho<1$ captures the effect of the species on habitat quality and, in turn, this degradation encourages the growth of the species.

While Eq. 4 is complex, it captures three ways for an invasive species to invade a region. On the economic side, the invasive can enter through both domestic and foreign trade as in the "introduction" term. On the ecological side, the ecological dispersal term identifies how the species moves between regions. The equilibrium of Eq. 4 without any removal effort occurs when the invasive population is equal to its carrying capacity.

\subsection{Economic Model}

The ecological model links to a spatial economic model that has three "sectors" in two regions (see Fig. 1). Both the import sector, represented by $V_{i}$, and the inter-regional trade sector, represented by $S_{i}$, contribute benefits but also create IAS transmission pathways. Each region's commodity production also generates value as a function of habitat quality and the IAS level but that production also degrades habitat quality. For this paper, trade levels are exogenously determined, which implies that inspection costs have a negligible effect on trade volume, and trade-restrictive policy is not utilized. ${ }^{2}$

Because trade flows are fixed, the relevant metric for the change in net benefits from trade is the direct cost of inspections, $\Omega$. We assume that these costs are linear in the inspections or

2 This assumption has little impact on the ecological side of the model because the key parameters $\left(\varpi_{i}, \omega_{i}\right)$ could easily represent either success at preventing invasion or at reducing trade. However, on the economics side, the assumption of fixed trade volumes matters because trade volumes may well be sensitive to inspection costs and because interactions across trade sectors and domestic production can produce ambiguous effects on the IAS (Costello and McAusland 2003). We leave these issues for future research. However, our model is sufficient to illustrate the potential implications of including a more realistic trade sector. 
$\Omega=\theta_{S_{i}} I_{S_{i}}+\theta_{S_{j}} I_{S_{j}}+\theta_{V_{i}} I_{V_{i}}+\theta_{V_{j}} I_{V_{j}}$, where the inspections are measured in terms of the volume of trade coming in that are inspected. $\theta^{\prime}$ s are the unit costs of doing the inspections of the shipments arriving into region $i$ via domestic trade $S$ or foreign trade $V$.

We model commodity production that is susceptible to damages from IAS through degraded habitat quality. Profits in each region are equal to the differences between total revenues from commodity production, $p_{i} Q_{i}\left(A_{i}, H_{i}\right)$, where $p_{i}$ is the output price in region $i$, less costs $\left(C_{i}\left(A_{i}, E_{i}, m_{i}\right)\right)$ of input use and the additional controls on the IAS, including habitat restoration and IAS removal efforts; $\pi_{i}=p_{i} Q_{i}\left(A_{i}, H_{i}\right)-C_{i}\left(m_{i}, A_{i}, E_{i}\right)$. By assuming that the price of output is not sensitive to changes in the level of the commodity produced, we are considering a situation where the regions are small producers on the world market, which is consistent with our treatment of the "trade" sectors.

The commodity production function has the following properties: $Q_{i}\left(A_{i}, 0\right)>0$ and $Q_{i}\left(0, H_{i}\right)>0$, which imply that the commodity can be produced with the natural conditions (e.g., organic agriculture or grazing native grasses), the non-natural input (e.g., fertilizer, replanting of faster growing feed crops), or some combination of both. ${ }^{3}$ The social planner maximizes the present value of commodity profits less the costs of treatment and prevention of the invasive, while facing constraints about IAS (Eq. 1 for both regions) and habitat stock (Eq. 2), and beginning from initial conditions for habitat quality and IAS level:

$$
\max _{I_{V_{i}}, I_{S_{i}}, A_{i}, m_{i}, E_{i}} \Psi=\int_{0}^{\infty} e^{-r t}\left\{\sum_{i=1}^{2} \pi_{i}(t)-\Omega(t)\right\} d t
$$

where $r$ is the discount rate. We leave for future research the question on how managing for other ecosystem service values associated with the habitat effects the choice of IAS controls.

In Table 1, we illustrate the general first order conditions for the control problem. The variables $\lambda_{i}$ and $\varphi_{i}$ are the shadow prices (costates) for the habitat and infestation states in region $i$, respectively. Because infestation is a bad, $\varphi_{i}$ is negative and is interpreted as the amount that the SP would be willing to pay on the margin to remove an additional IAS. $\varphi_{i}$ can also be interpreted, therefore, as the value of the damages from a marginal change in the stock of the IAS. $\lambda_{i}$ is the value associated with a marginal improvement in the habitat. Although a closed form solution to the system of equations is mathematically intractable at this level of generality, we derive intuition from the FOCs. First, Eq. 6 states that the value of the marginal future damages avoided (marginal damages are equal to the marginal reduction in the IAS transmission multiplied by the present value shadow price of damages in time $t$ ) is equal to the marginal cost of inspection of foreign goods. Equation 7 states the same for inspections of domestic goods.

Here, commodity production reduces habitat quality but restoration can offset that effect; the SP finds the optimal level of restoration using Eq. 9. To determine the optimal level of the commodity production, the SP uses Eqs. 8 and 9, finding the level where the value of the marginal product of the output is equal to the marginal cost of using the non-habitat input (second term) plus the marginal damages to the habitat, which are mitigated by the optimal level of habitat restoration ${ }^{4}$ :

3 We also impose that the marginal product of using the non-natural input is greater than or equal to the marginal product from the natural habitat $\left(\partial Q / \partial A_{i} \geq \partial Q / \partial H_{i}\right)$, everything else being equal. In other words, the non-natural input is more productive per unit at the margin.

4 The equation is derived assuming an interior equilibrium. 
Table 1 Social planner first order conditions in current value terms

\begin{tabular}{ll}
\hline Inspection of foreign trade & $I_{V_{i}}\left(\varphi_{i} \frac{\partial f_{i}(\bullet)}{\partial I_{V_{i}}}-\theta_{V_{i}}\right)=0$ \\
Inspection of domestic trade & $I_{S_{i}}\left(\varphi_{i} \frac{\partial f_{i}(\bullet)}{\partial I_{S_{i}}}-\theta_{S_{i}}\right)=0$ \\
Level of non-natural input & $A_{i}\left(p_{i} \frac{\partial Q_{i}(\bullet)}{\partial A_{i}}-\frac{\partial C_{i}(\bullet)}{\partial A_{i}}-\lambda_{i} \frac{\partial D_{i}(\bullet)}{\partial A_{i}}\right)=0$ \\
Level of habitat restoration & $m_{i}\left(-\frac{\partial C_{i}(\bullet)}{\partial m_{i}}+\lambda_{i} \frac{\partial g_{i}(\bullet)}{\partial m_{i}}\right)=0$ \\
Level of IAS removal & $E_{i}\left(-\frac{\partial C_{i}(\bullet)}{\partial E_{i}}-\varphi_{i} \frac{\partial R_{i}(\bullet)}{\partial E_{i}}\right)=0$ \\
Shadow price of habitat & $\frac{d \lambda_{i}}{d t}-r \lambda_{i}=-\left\{p_{i} \frac{\partial Q_{i}(\bullet)}{\partial H_{i}}+\lambda_{i} \frac{\partial g_{i}(\bullet)}{\partial H_{i}}+\varphi_{i} \frac{\partial f_{i}(\bullet)}{\partial H_{i}}\right\}$ \\
Shadow price (cost) of IAS & $\frac{d \varphi_{i}}{d t}-r \varphi_{i}=-\left\{-\lambda_{i} \frac{\partial D_{i}(\bullet)}{\partial x_{i}}+\varphi_{i}\left(\frac{\partial f_{i}(\bullet)}{\partial x_{i}}-\frac{\partial R_{i}(\bullet)}{\partial x_{i}}\right)+\varphi_{j} \frac{\partial f_{j}(\bullet)}{\partial x_{i}}\right\}$ \\
\hline
\end{tabular}

$$
\underbrace{p_{i} \frac{\partial Q_{i}}{\partial A_{i}}}_{\begin{array}{c}
\text { Value } \\
\text { marginal } \\
\text { product }
\end{array}}=\underbrace{\frac{\partial C_{i}}{\partial A_{i}}}_{\begin{array}{c}
\text { Marginal } \\
\text { costs }
\end{array}}+\underbrace{\text { Marginal costs }}_{\text {Marginal product of restoration }} \begin{gathered}
\begin{array}{c}
\text { Marginal } \\
\text { damages }
\end{array} \\
\left.\frac{\partial C_{i}}{\partial m_{i}} / \frac{\partial g_{i}}{\partial m_{i}}\right)
\end{gathered}
$$

The marginal value of habitat is derived from habitat quality's impact on commodity production, habitat's regenerative rate, and the value of reducing the ability of the invasive to invade and establish (Eq. 11). ${ }^{5}$ The marginal value of the damages from an invasive species (Eq. 12) is a function of the deterioration of the habitat quality, as mitigated by restoration efforts, and, through the ecological dispersal process, the level of infestation in the other region. The term $\varphi_{j}\left(\partial f_{j} / \partial x_{i}\right)$ represents the amount the SP is willing to pay to eliminate the ecological dispersal process to reduce the risk of the IAS from spreading between regions.

\section{Numerical Analysis}

To explore the behavior of the bioeconomic model and to determine the portfolio of policies that are optimal in different settings, we solve for the numerical steady-state equilibrium using Matlab. In order to solve the system, we specify a particular profit function. We assume that profits are equal to:

$$
\pi_{i}=p_{i}\left(v_{i, 1} A_{i}^{\alpha}+v_{i, 2} H_{i}^{\alpha}\right)^{1 / \alpha}-w_{i} A_{i}-c_{i} m_{i}^{2}-\gamma_{i} E_{i}^{2}
$$

where $c_{i}$ is the cost per unit to restore habitat, $w_{i}$ is the cost per unit of input, $\gamma_{i}$ is the cost to remove the IAS, $v_{i, 1}$ is the conversion factor of a unit of input, and $\alpha$ is the elasticity of substitution between the agricultural input and habitat. This production function for the commodity (say, crop or livestock) displays a constant elasticity of substitution between the two inputs: $A_{i}$ and the habitat $H_{i}$.

With this profit function, the optimal control problem is non-linear (see, for example, Bryson 1998). ${ }^{6}$ We utilize the constrained non-linear equation solver KNITRO in Matlab,

5 The particular components on the right hand side of Eq. 13 are the value marginal product, the marginal ecological production, the marginal reduction in the transmission of IAS into region $\mathrm{i}$, and the reduction in the reproductive rate of the IAS.

6 We leave the characterization of the transitional dynamics for future research. See Bryson (1988) for more description of the methods for solving multi-dimensional optimal control problems. 
which permits us to consider optimal interior steady-state solutions (all controls are positive) and optimal boundary solutions (some or all controls are set to zero). A table of parameter symbols, definitions, and levels that are used in the simulations appears in the supplementary material.

Although the model is set-up to permit foreign trade into both regions, to emphasize the spatial heterogeneity across regions and to limit the number of cases presented, we focus here on the scenario where one region (region 1) interacts with economic forces exogenous to the model (in other words has foreign trade), while the other region captures a region without foreign trade (region 2). Without loss of generality, we denote this scenario port-inland.

In our numerical analysis, we focus on two questions. First, we compare the results from the fully connected model to those from a no-linkage model (no trade or ecological dispersal) to highlight how IAS pathways contribute to spatially differentiated patterns of control. We also introduce each linkage independently to illustrate how adding in the linkage alters the control strategies.

Second, we compare predictions when the planner has all of the controls available to a situation where certain controls are not available. For example, the planner can engage in removal and restoration but inspections are not considered, even though IAS populations are transmitted through trade. We are, therefore, able to investigate how our more general set-up yields potentially different policy conclusions from analyses that do not consider all of the controls in one framework.

With the large number of parameters in the model, we choose our base set of parameters to minimize the potential differences in our results due to the levels rather than processes. For example, we assume that both the per unit cost of domestic $\left(\theta_{s}\right)$ and foreign inspections $\left(\theta_{v}\right)$ and the contribution to IAS growth from these transmission sources $\left(\beta_{1, i}=\beta_{2, i}\right)$ are equal. The difference in the results between these cases, therefore, is driven by how these transmission pathways enter the model. We also assume that the cost of removal efforts (e.g., herbicide, pesticide application) is less than the costs of habitat restoration (e.g., planting native species, plowing fields). The online supplementary material provides additional explanation for the choices of parameters and the full set used in the base case.

\subsection{Implications of Multiple IAS Dispersal Pathways}

We begin by assuming that the regions are homogeneous ecologically and economically, except for the port-inland structure. In this analysis, our results focus on percentage differences between the steady-state level with open transmission pathways and the level with no linkages (Table 2). A positive (negative) level indicates that the level is higher (lower) by that percentage in the open transmission pathways case. The no-linkage equilibrium is characterized by levels of the IAS at approximately $68 \%$ of its carrying capacity and habitat quality level equal to $52 \%$ pristine habitat, with $22 \%$ of the total costs spent on removal activities and $78 \%$ spent on restoration. The levels of controls and the states are equal across the regions, because the port-inland structure is not relevant in the case without trade and ecological linkages.

Introducing an ecological dispersal pathway increases the IAS population by $10 \%$ in each patch. This increase is due in part to ecological dispersal increasing the overall growth rate of the invasive species and the planner choosing to implement lower levels of removal activities (decrease of $11.5 \%$ ). At the same time, the planner chooses slightly more restoration $(0.75 \%)$, higher input use $(0.18 \%)$, and lower production $(-0.2 \%)$. Therefore, while the invasive population increases $10 \%$, output from the regions changes little. 


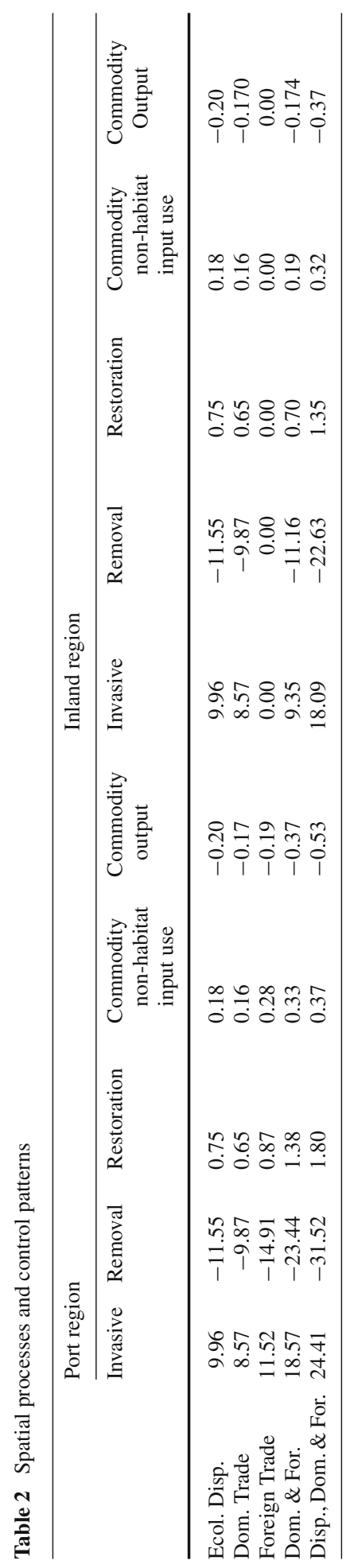


The result with domestic trade pathways (without ecological dispersal) is similar to the case with just ecological dispersal, with a slightly lower impact on the invasive population level. To see why the changes are similar but lower in this case, we focus on the portion of the growth term in Eq. 1 for region i that captures ecological dispersal and domestic trade, $\left[\mathrm{b}_{\mathrm{i}}+\beta_{\mathrm{i}} \mathrm{G}\left(\mathrm{S}_{\mathrm{i}}, \mathrm{I}_{\mathrm{si}}\right)\right] \mathrm{x}_{\mathrm{j}}$. Unlike ecological dispersal that cannot be controlled directly, inspections work against trade's tendency to increase the IAS population, leading to reductions in the net growth rate of the invasive $\left(\partial \mathrm{G} / \partial \mathrm{I}_{\mathrm{si}}<0\right)$. We find that inspections reduce the standing stock of invasive population (an increase of only $8.5 \%$ relative to a $10 \%$ increase in the case of ecological dispersal). The inspections lead to a lower increase in the IAS population, even though domestic trade inspection accounts for less than $1 \%$ of the costs spent on invasive management. Removal and restoration still account for around $22 \%$ and $77 \%$ of the control costs, respectively.

Introducing foreign trade pathways (without domestic trade and without ecological dispersal) leads to a larger increase in the port region's invasive population than seen in the cases with just domestic trade or just ecological dispersal. Inspections can significantly reduce the level of incoming IAS but the level cannot be driven to zero $\left(V_{i} \neq 0\right.$, see above). Output in the port region is lower overall but is higher than inland due to greater use of the non-habitat input and the higher restoration efforts.

Layering the domestic trade pathways onto the case with foreign trade creates non-linear interactions across the pathways. We see, for example, a 9.35\% increase in the inland region's invasive population instead of an $8.57 \%$ increase with just domestic trade, as compared to the no-linkages case. Similarly, we see a much larger increase in the invasive population in the port region than with either foreign or domestic trade alone (Table 1) because the IAS in the port region now comes from two rather than one sources. Interestingly, the greater increase in invasive in the port region translates into higher increases in the inland invasive population than in the case with just domestic pathways (9.3-8.6\%). Our model, therefore, is capturing the potential ripple effect throughout a system due to introductions from outside an area.

Layering another source of the invasive for each region by permitting ecological dispersal in addition to both trade pathways leads to the largest increase in the invasive population (density levels in the port are $84 \%$ and inland are $80 \%$ ). Removal efforts also see significant disinvestment as the returns to removal are lower with higher invasive population size (smaller overall reduction per dollar invested in removal). Restoration efforts, however, are higher to offset the increase in damages to the habitat. The restoration efforts are not enough, however, to mitigate all of the damages from the invasive, as evident by the decrease in the level of the habitat quality (down from $51-50 \%$ between the case with ecological dispersal only to the case with all linkages).

Figure 1 illustrates the distribution of removal, restoration, and domestic inspection costs across the system. Because in the ecological and domestic pathways cases there is no difference in the stock and control levels across the system, we find that costs are shared equally across the port and inland region. The allocation of control efforts do change with the introduction of the foreign trade, where we see that more removal efforts are targeted in the inland region. Overall, the distribution of restoration activities changes very little, with a very slight increase in the port activity due to foreign trade.

Relative to the case with just one transmission pathway, we find that with both domestic and foreign trade, the planner shifts towards inspecting the goods arriving inland and away from inspecting goods arriving into the port. This redistribution of inspection effort is evident in the distribution of the cost shares in Fig. 1. When all linkages are present, the ecological dispersal increases the inland region's IAS population, which causes some of the domestic inspection efforts to shift back to inspecting the imports from the inland region into the port. 

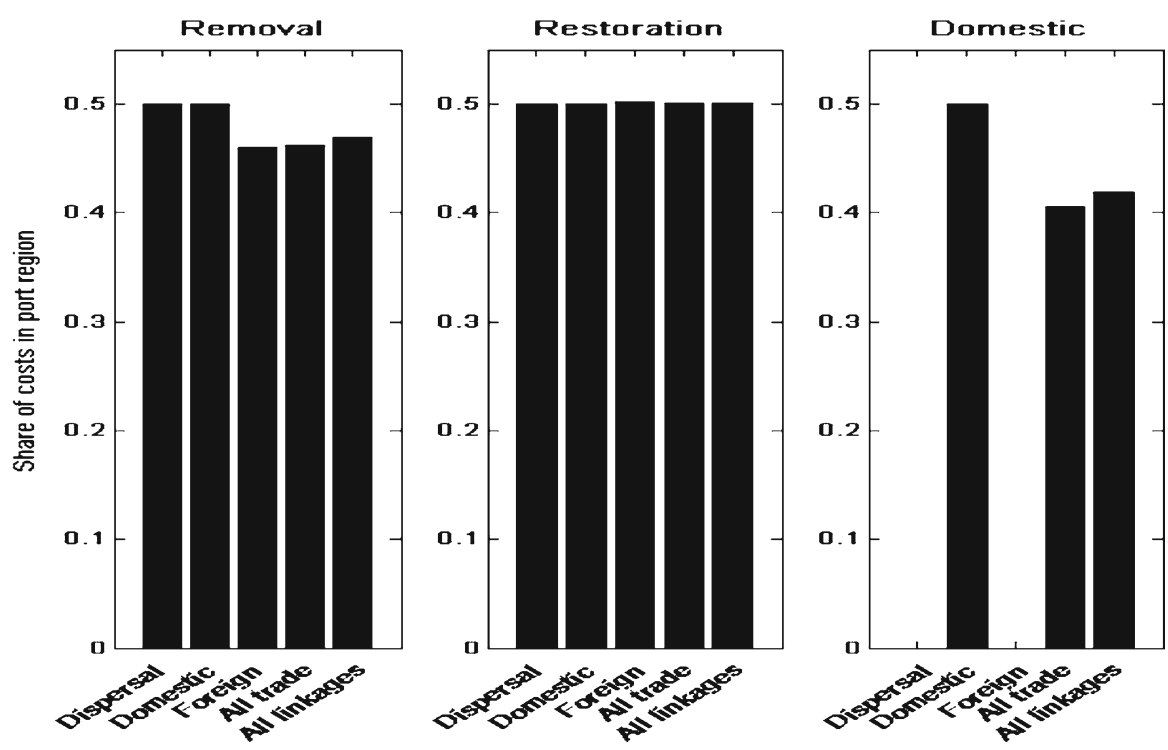

Fig. 1 Distribution of control costs across the port and inland regions. Note: Restoration is changing across the cases but the magnitude is less than $1 \%$

What are the potential interactions of spatial heterogeneity in costs and the spatial linkages? To address this question, we employ a representative sample of parameter ranges with a focus on relative differences between spatially specific and general economic and ecological parameters. In particular, we illustrate the results for a range of differences in the costs of the non-habitat input $\left(w_{i}\right)$, in the costs of removal $\left(\gamma_{i}\right)$ and in the restoration costs $\left(c_{i}\right)$.

The ratio of the cost parameter in region 2 (inland) to the cost parameter in region 1 $\left(w_{2} / w_{1}, \gamma_{2} / \gamma_{1}\right.$ or $\left.c_{2} / c_{1}\right)$ demonstrates the differences between regions with no economic or ecological linkages in the system (Fig. 2). To isolate these parameter differences, all of the other parameters are equal across the two regions, which contain the homogeneous case when the ratio is equal to one (and the levels are equal for each of the three cases). To create Fig. 2's depiction of the impact of the relative cost parameters on the invasive population, habitat, input use, removal, and restoration activities in region 2 , we vary $w_{2}$ holding $w_{1}$ constant (with no changes occurring in region 1, the port).

As $w_{2}$ decreases $\left(w_{2} / w_{1}<1\right)$, the level of the input use increases, because per unit costs decrease. The greater use of the input leads to higher levels of damage to the habitat that in turn allow greater levels of the invasive population. The planner responds to the lower habitat quality and higher invasive population by increasing both restoration and removal activities. Restoration, however, increases at a much faster rate than removal activities due to restoration being able to negate directly the damages from both the higher invasive population and greater use of the non-habitat input.

Not surprisingly, lower costs of removing the invasive species $\left(\gamma_{2} / \gamma_{1}<1\right)$ leads to higher levels of removal activities and to lower invasive population levels. What is surprising, however, is the small effect that removal costs have on restoration, input, and habitat levels. A similar result holds for restoration costs, which do not have a significant effect outside of the obvious inverse relationship between costs and activity levels. In fact, non-habitat input costs affect the level of restoration activities more than restoration costs. This response 

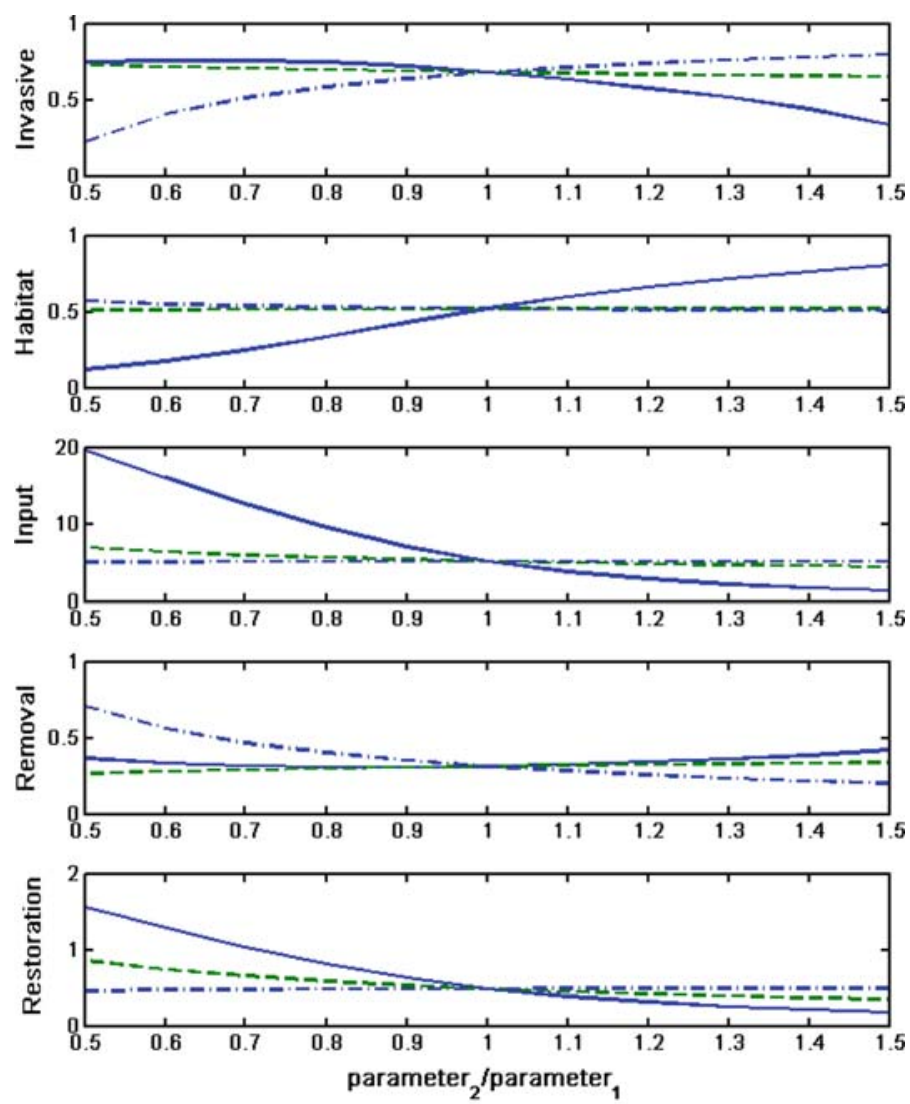

-Non-habitat input $\left(w_{2} / w_{1}\right)---$ Restoration $\operatorname{costs}\left(c_{2} / c_{1}\right) \ldots-\cdots$ Removal $\operatorname{costs}\left(\gamma_{2} / y_{1}\right)$

Fig. 2 Sensitivity analysis on the relative costs of the input $\left(\mathrm{w}_{\mathrm{i}}\right)$, restoring the habitat $\left(\mathrm{c}_{\mathrm{i}}\right)$, and removing the invasive $\left(\gamma_{i}\right)$ with no economic or ecological linkages

derives from the large increase in the non-habitat input and the corresponding damages to the habitat, where restoration activities offset the greater level of damages.

Building on the intuition from the case with no linkages, we investigate how the distribution of inspection, removal, and restoration costs are affected by spatial heterogeneity, meaning the differences in regional costs, in the presence of all pathways. (The change in the levels of the controls and states are provided in supplementary material.) First, for removal costs $(\gamma)$ at low ratios, $\gamma_{2} / \gamma_{1}<<1$, the SP spends less on inspecting goods moving from the inland (region 2) to the port region (panel a in Fig. 3) and spends a lower share of inspection costs on inspecting foreign shipments than at high cost ratios (panel b in Fig. 3). The regional difference in costs, however, has a very small effect on the distribution of spending on restoration (panel d in Fig. 3).

These results stem from the size of the IAS population (see supplementary material). Relative to the case when $\gamma_{2} / \gamma_{1}=1$, with low inland removal cost ratios $\left(\gamma_{2} / \gamma_{1}<1\right)$ both regions have low IAS populations, particularly the inland region. The low invasive population levels imply lead to less of a need to spend additional resources inspecting goods moving to the port from the inland region. At the same time, the SP attempts to maintain lower invasive 

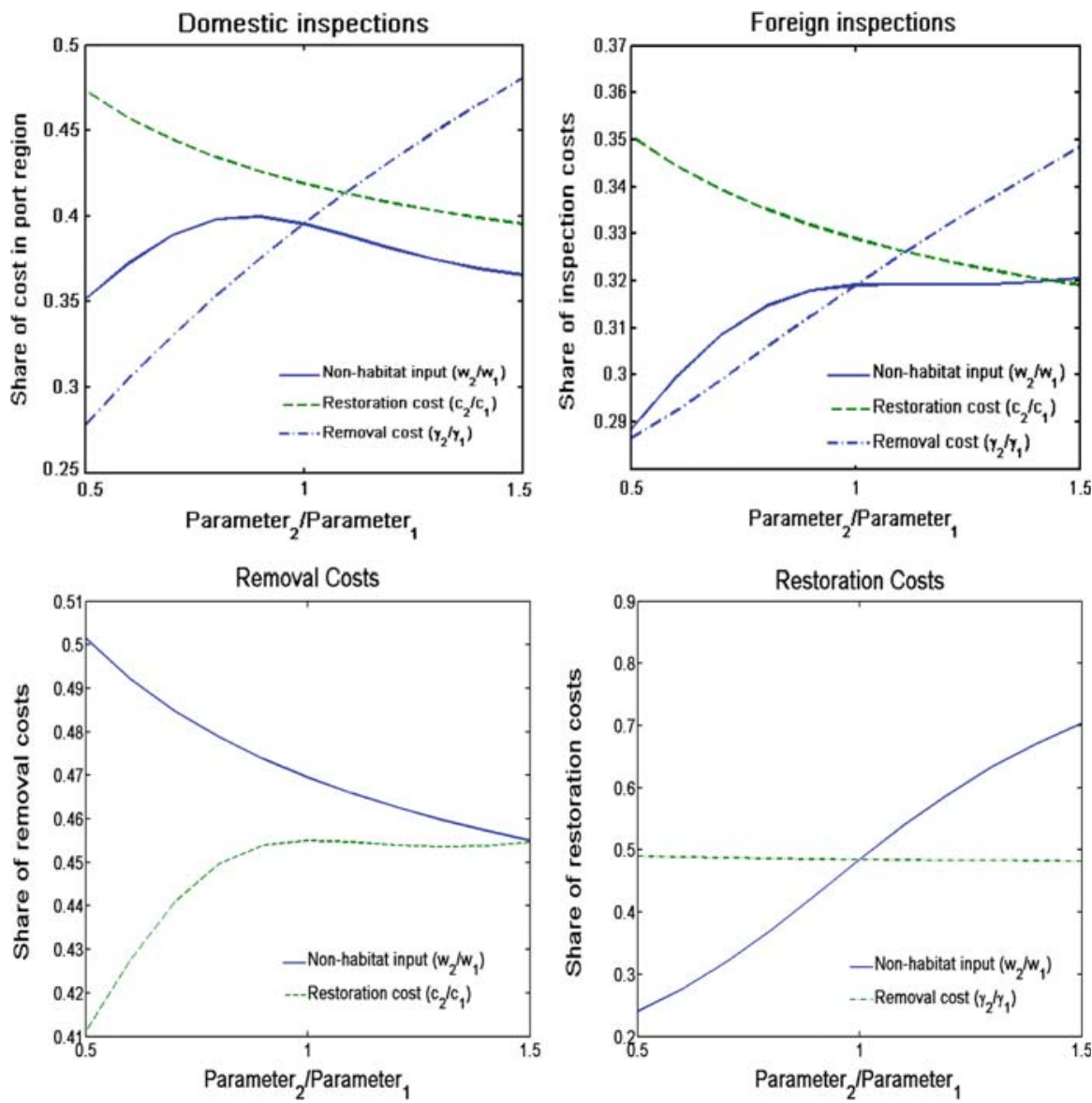

Fig. 3 Sensitivity analysis on the share of control costs. Note: Panel a illustrates the share of domestic inspections spent in the port region. Panel $\mathbf{b}$ represents the share of inspection costs spent on foreign inspections. Panel $\mathbf{c}$ illustrates the share of removal costs spent in port region and panel $\mathbf{d}$ the share of restoration costs spent in the port region

stocks in the inland region by increasing inspections from the port. Here, the higher domestic inspection levels in the inland region outweigh the slightly higher foreign inspections at the port.

Restoration costs generate the opposite effects (Fig. 4). In this case, as the cost of restoration decreases inland, the SP puts more resources into inspecting the shipments from the inland region, but the overall share is still weighted more to inspecting goods from the port region (less than 0.5 ). The cheaper restoration cost leads to greater use of the non-habitat input, less investment in removal efforts inland (but still a greater share of efforts occur inland as depicted in Fig. 3 panel c), and increases in the invasive population. The level of foreign inspections in the port and domestic inspections into the inland region go down, but the rate of decrease is greater in domestic inspections (see supplementary material). Overall, the SP cares less about the invasive because the costs of mitigating the damages are lower. The greater rate of decline of domestic inspections leads to a greater share of the inspection costs being spent on foreign inspections (panel b Fig. 3). 


\section{Port region}

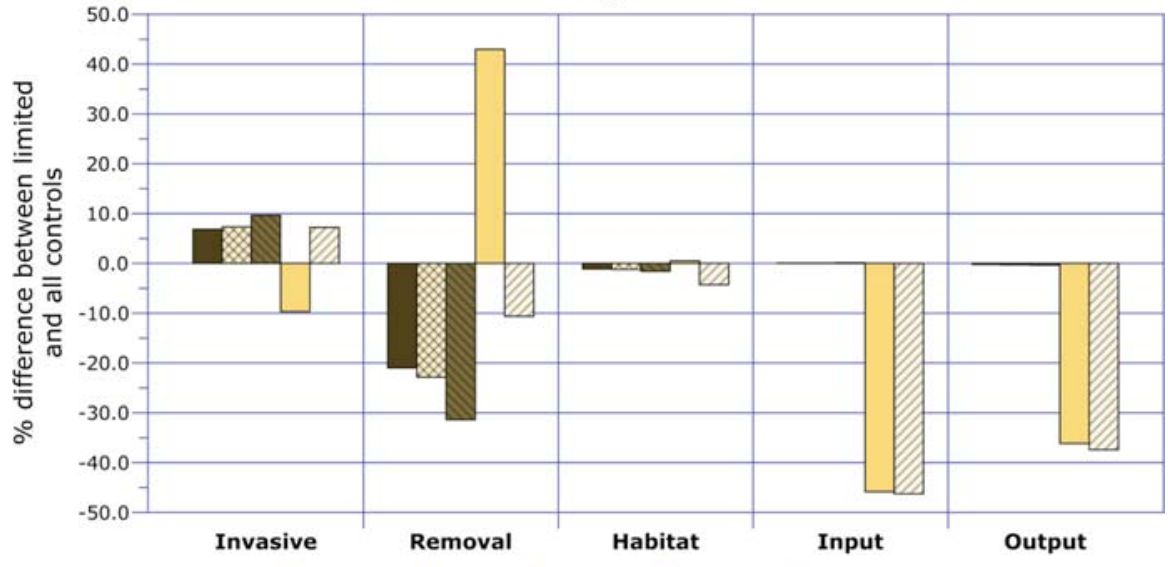

No Dom. \& No For. $\mathbf{A}$ No Trade No Rest. $/ /$. No Trade \& No Rest.

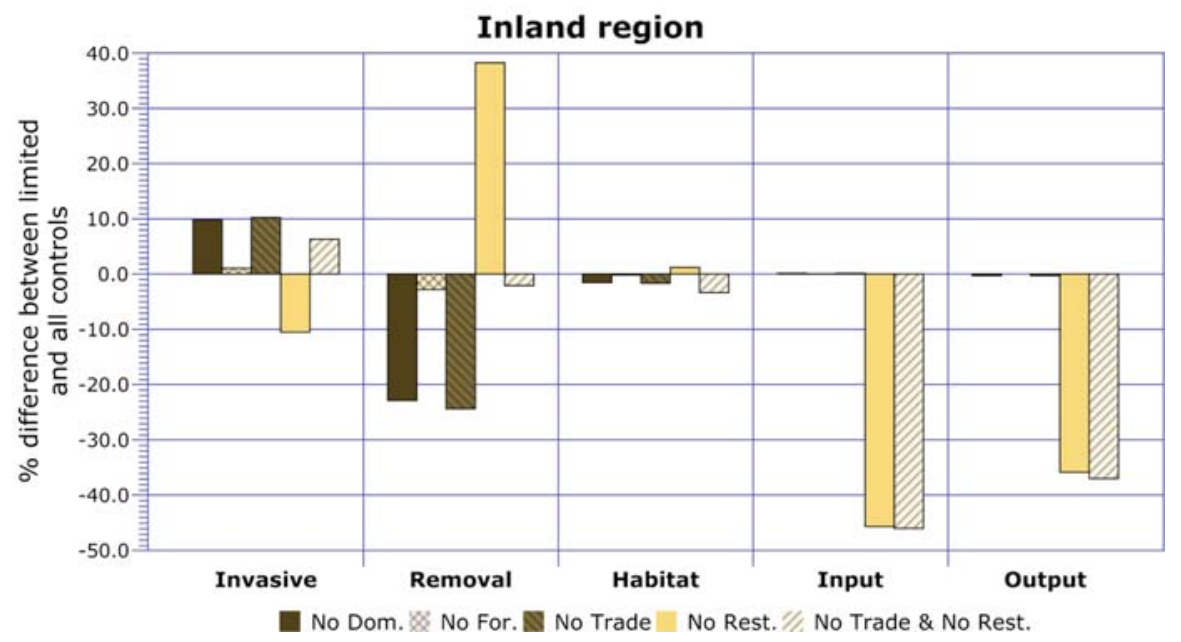

Fig. 4 Impacts of restricting the control portfolio. Note: The impacts are measured as deviations off of the case when all controls are included

Across the different analyses, our findings reveal the introduction of additional pathways is neither a simple average nor an additive combination of the results with more limited transmission pathways. For example, in Table 1, the additive combination of ecological dispersal, domestic trade, and foreign trade for the invasive population in the port region would be a $29.5 \%$ change for the case with no linkages. The model with all of the linkages results in only a $24 \%$ change from the same base case. In our analysis, therefore, there are synergies in the control decisions when all the transmission pathways are incorporated that result in the smaller increase in IAS population. These synergies would not be part of the solution set in models with more limited transmission pathways. Similarly, we find that control strategies in the presence of spatially linked processes (IAS transmission) interact in a non-linear way with the degree of spatial heterogeneity. 


\subsection{Implications of Limited Control Options}

We now ask the question: how different are the model predictions when we restrict the control options available to the social planner? In particular, we are interested in the changes to the invasive and habitat stock and in the level of the controls that are permitted. Our analysis will, therefore, shed light on whether previous IAS modeling efforts that only consider removal efforts (and are second-best in our setting) give markedly different policy guidance than models that include restoration and/or trade inspections as well.

Before running the numerical examples, the first order conditions provide intuition on the likely impact of restricting the control set. With restoration, the planner equates the marginal return from investing in restoration to the user cost of the habitat (Eqs. 9 and 11). The latter is a function of the economic value of habitat in production $\left(p_{i}\left(\partial Q_{i} / \partial H_{i}\right)\right)$, the cost of utilizing the habitat $\left(1 /\left(r_{i}+\partial g_{i} / \partial H_{i}\right)\right)$, and the damage from of the invasive alien species $\left(\phi_{i}\left(\partial f_{i} / \partial H_{i}\right)\right)$. Without restoration as a policy option, the planner adjusts the level of the non-habitat input directly to account for the user cost of the habitat (Eq. 13 is modified as Eq. 11 is used to solve for the shadow price rather than Eq. 9), but cannot mitigate the damage. We should expect, therefore, to see a decrease in the level of non-habitat input relative to the case when restoration is available. Whether this change, however, affects the level of production on the land depends also on the changes to habitat quality.

As above, we begin by assuming that the only heterogeneity in the system is due to the port-inland structure. The cases we consider are: no domestic inspections, no foreign inspections, no trade inspections, no restoration, and no trade and restoration. In all cases, the SP still has the ability to adjust output and removal efforts. Figure 4 illustrates for each region the percent difference between the cases and the level when all controls are available (removal, restoration, and inspections).

Under the current assumptions, models that do not consider inspections predict high invasive populations and slightly lower levels of habitat quality. These models also provide policy guidance that leads to substantial reductions in the optimal amount of removal activities. Across the regions, patterns are qualitatively identical with slightly lower percentage deviations in the inland region. Overall, the optimal use of the land (use of non-habitat input and output levels) are only slightly off the mark. Interpreted differently, a manager who cannot perform inspections does not make very different land use decisions than those that can but the landscape looks different in terms of invasive populations and habitat quality when the manager is constrained from using inspections.

On the other hand, an IAS model (or a constrained manager) that does not include restoration as part of the portfolio of control options results in a significant over emphasis on removal activities and a severe deviation from the optimal use of the land. For example, the reduction in output compared to the full set of control options is on the order of $40 \%$ in both regions. The reduction in output is optimal under the restrictive control set, but reveals the cost of not having that policy option and the potential level of error made by models that do not incorporate restoration as an option. Figure 4 also illustrates the non-linear cumulative effects of not including restoration and trade on the invasive populations and removal efforts. Although the predictions on the direction of the deviations differ in the invasive and removal efforts, the significant reduction in output is consistent across the two cases that omit restoration activities as a policy tool.

Does spatial heterogeneity exacerbate or mitigate the potential costs of second-best policies? To answer this question, we undertake a sensitivity analysis for the no trade, no restoration, and no trade and restoration cases (Fig. 5). Changing the relative costs of using the non-habitat input in the inland region has very little effect on the distortions in the port region 

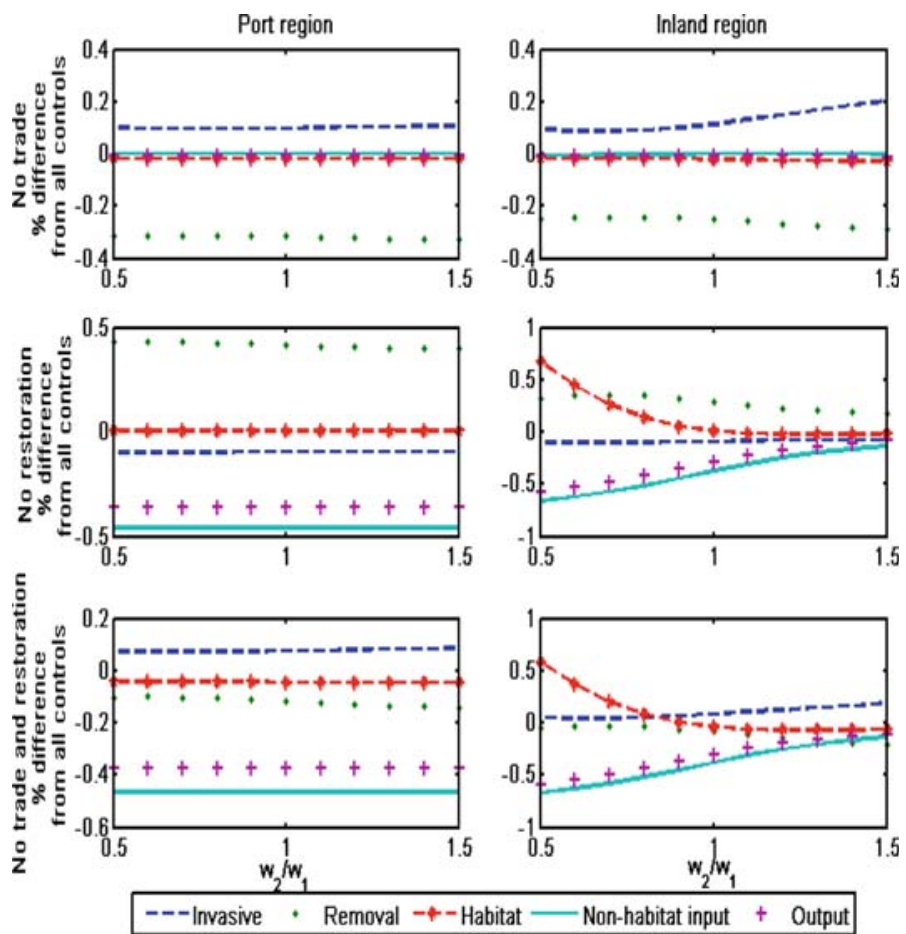

Fig. 5 Sensitivity analysis on the implications of limited control portfolio with respect to changes in the cost of the non-habitat input. Note: The impacts are measured as deviations off of the case when all controls are included. For example, a decrease of 0.5 is a $50 \%$ decrease in the level from the case when all controls are permitted

where the level remains virtually unchanged. In the inland region, however, the magnitude of the distortions is affected, especially the predicted levels of habitat quality, non-habitat input, and output in the cases when restoration is omitted from the control set.

With $\mathrm{w}_{2}<<\mathrm{w}_{1}$, the potential error associated with factors is on the order of $50 \%$. As the cost of $w_{2}$ increases, the magnitudes of errors decrease due to the smaller differences between the results with the limited portfolio and the first-best solution, which stems from the low input use in the first best setting when $\mathrm{w}_{2}>>\mathrm{w}_{1}$ (see supplementary figure $\mathrm{S} 1$ ). With little use of the habitat in the first best setting, the potential effect of reducing the control set is muted.

The predictions regarding the level of removal efforts and invasive population follow a different pattern from the production variables. In the case with no trade inspections, the percent difference between the invasive population with the full set of controls increases with $\mathrm{w}_{2}$ (and is positive) due to underinvestment in removal efforts. The opposite holds for the case of no restoration, where the overinvestment in removal efforts to mitigate the damages to habitat from the invasive species leads to slightly lower levels of the invasive population.

Similar analysis for the costs of restoration (no trade case only) and the costs of removal are presented in the supplementary material. Overall, the patterns are qualitatively identical for the case of removal costs. With respect to restoration costs, we find that there is very little change in the production variables and similar effects on the invasive and removal efforts as the no trade case in Fig. 5. 


\section{Discussion}

Invasive alien species (IAS) are a natural resource management problem that has multiple points of control across space. We develop a unique 2-region economic-ecological model that captures simultaneously the role of introductions from inside (domestic and ecological dispersal) and outside (foreign trade) the system on IAS populations, and the role of several control options - inspections, restoration, and removal efforts - to mitigate IAS damages. Incorporating all of these pieces allows us to see trade-offs among controls and across space and identify the implications of not including the full portfolio of management options in models of IAS control.

As individual transmission pathways, foreign trade's impact on controls and on IAS populations appears larger than the impact of domestic trade and ecological dispersal pathways. However, our results demonstrate that when there are multiple pathways for IAS transmission, control strategies are not simply additive or average combinations of the results with a limited set of pathways because system-wide interactions are non-linear. These results and our analysis of reduced sets of control options, signal that policy recommendations from modeling efforts that only consider one of the dimensions and/or control strategies may be far from efficient. Similarly, control strategies in the presence of spatially linked processes interact in a non-linear way with the degree of spatial heterogeneity. IAS control models that focus on only part of the portfolio of options available to planners can provide incomplete and often misguided policy advice both in terms of where to target limited resources and the level of controls to apply. Removing restoration from the control set, for example, leads to excessive reliance on removal efforts and significant deviations from the optimal use of the land. Predictions from more limited models are also affected by the spatial heterogeneity in the system. Overall, our results imply that using spatial characteristics (e.g., existence of a type of habitat) as the basis for making conservation policy can make erroneous predictions in the presence of spatial processes for which even the direction of error is difficult to determine.

Some interesting extensions to our model would be to endogenize the level of the trade between the two domestic regions, to investigate the implications of having two regional planners that might or might not cooperate, and to consider the case where the regulator is restricted from applying spatially-explicit control policies. The primary lesson is that focusing on a subset of transmission pathways, on only one or two controls, or on a single region, misses important interactions that would limit that focused effort's ability to generate policy recommendations.

Open Access This article is distributed under the terms of the Creative Commons Attribution Noncommercial License which permits any noncommercial use, distribution, and reproduction in any medium, provided the original author(s) and source are credited.

\section{References}

Bryson A (1998) Dynamic optimization. Pearson Education, New York

Carter CA, Chalfant JA, Goodhue RE, Zalom F, McKee G (2006) Biology and economics of invasive species: spatial and temporal interactions. PREISM Workship, Washington, DC

Cohen AN, Carlton JT (1998) Accelerating invasion rate in a highly invaded estuary. Science 279:555-558

Costello C, McAusland C (2003) Protectionism, trade, and measures of damage from exotic species introductions. Am J Agric Econ 85:964-975

Costello C, McAusland C, Springborn M, Solow A (2007) Unintended biological invasions: does risk vary by trading partner?. J Environ Econ Manag 54:262-276 
Cumming GS (2002) Habitat shape, species invasions, and reserve design: insights from simple models. Conserv Ecol 6:3

Davies K, Sheley R (2007) A conceptual framework for preventing the spatial dispersal of invasive plants. Weed Sci 55:178-184

Eiswerth ME, Kooten GCV (2002) Uncertainty, economics, and the spread of an invasive species. Am J Agric Econ 85:1317-1322

Enserink M (1999) Predicting invasions: biological invaders sweep in. Science 285:1834-1836

Finnoff D, Shogren JF, Leung B, Lodge DM (2005) The importance of bioeconomic feedback in nonindigenous species management. Ecol Econ 52:367-381

Gordon D (1998) Effects of invasive, non-indigenous plant species on ecosystem processes: lessons from Florida. Ecol Appl 8:975-989

Hastings A, Byers JE, Crooks JA, Cuddington K, Jones CG, Lambrinos JG, Talley TS, Wilson WG (2007) Ecosystem engineering in space and time. Ecol Lett 10:153-164

Hof J (1998) Optimizing spatial and dynamic population-based control strategies for invading forest pests. Nat Resour Model 11:197-216

Horan R, Perrings C, Lupi F, Bulte E (2002) Biological pollution prevention strategies under ignorance: the case of invasive species. Am J Agric Econ 84:1303-1310

Horan R, Wolf CA, Fenichel EP, Mathews KH (2005) Spatial management of wildlife disease. Rev Agric Econ 27:483-490

Huenneke LF, Hamburg SP, Koide R, Mooney HA, Vitousek PM (1990) Effects of soil resources on plant invasion and community structure in Californian serpentine grassland. Science 71:478-491

Jones CG, Lawton JH, Shachak M (1994) Organisms as ecosystem engineers. Oikos 69:373-386

Kaiser B, Roumasset J (2002) Optimal public control of exotic species: preventing the brown tree snake form invading Hawaii. WEA annual meetings 2002

Leung B, Lodge DM, Finnoff D, Shogren J, Lewis MA, Lamberti G (2002) An ounce of prevention or a pound of cure: bioeconomic risk analysis of invasive species. Proc Biol Sci 269:2407-2413

Margolis M, Shogren JF, Fischer C (2005) How trade politics affect invasive species control. Ecol Econ 52:305-313

McAusland C, Costello C (2004) Avoiding invasives: trade related policies for controlling unintentional exotic species introductions. J Environ Econ Manag 48:954-977

Mehta SV, Haight RG, Homans FR, Polasky S, Venette RC (2007) Optimal detection and control strategies for invasive species management. Ecol Econ 61:237-245

Olson LJ (2006) Economics of terrestrial invasive species: a review of the literature. Agric Resour Econ Rev 35:178-194

Olson LJ, Roy S (2005) On prevention and control of an uncertain biological invasion. Rev Agric Econ 27:491-497

Olson LJ, Roy S (2008) Controlling a biological invasion: a non-classical dynamic economic model. Econ Theory 36:453-469

Sanchirico JN, Maldavkar U, Hastings A, Wilen J (2006) When are no-take zones an economically optimal fishery management strategy?. Ecol Appl 16(5):1643-1659

Sharov A, Liebhold A (1998a) Bioeconomics of managing the spread of exotic pest species with barrier zones. Ecol Appl 8:833-845

Sharov A, Liebhold A (1998b) Model of slowing the spread of gypsy moth (Lepidoptera: Lymantriidae) with a barrier zone. Ecol Appl 8:1170-1179

Sharov AA (2004) Bioeconomics of managing the spread of exotic pest species with barrier zones. Risk Anal 24:879-892

Skonhoft A, Olaussen JO (2005) Managing a migratory species that is both a value and pest. Land Econ 81

Wainger L, King DM (2006) Choosing efficient treatment options by assessing costs and benefits in a spatial risk-based optimization framework. PREISM Workshop, Washington, DC 